\title{
Design, Development and Evaluation of Manual Vegetable Transplanter
}

\author{
Kanakam Yaswanth Kumar*, V. Narendra Reddy, S. C. Moses, \\ R. N. Aalam and Sandeep Singh
}

\begin{abstract}
Department of Farm Machinery and Power Engineering, Vaugh Institute of Agricultural Engineering and Technology (VIAET), Sam Higgin bottom University of Agriculture, Sciences and Technology, (SHUATS) Prayagraj, (Uttar Pradesh), India
\end{abstract}

*Corresponding author

\section{A B S T R A C T}

\section{Keywords}

Manual Vegetable

Transplanter,

Vegetable crops

\section{Article Info}

Accepted:

07 December 2020

Available Online:

10 January 2021
The present study was carried out during the year 2020 to design, development and evaluation of manual vegetable transplanter on two different types of vegetable crops i.e., tomato and chilli. The manual vegetable transplanter consists of different components like frame, wheels, supporting rod, furrow covering device, seedling stand, seedling delivery tube, hopper, jaw opening pedal, handle and jaw mouth. The seedling delivery tube penetrates into the soil by applying little force while holding with handle, seedling is dropped into seedling delivery tube then the jaw is opened by pressing the pedal. The work demonstrates the application of engineering techniques to reduce the labour efforts and time required for transplanting. The results obtained from the trial tests concluded that transplanter functioned properly. The effective field capacity was $0.0057 \mathrm{ha} / \mathrm{h}$ for tomato and effective field capacity for chilli is $0.0029 \mathrm{ha} / \mathrm{h}$. Field efficiency was found to be $95 \%$ for tomato and $96.66 \%$ for chilli. The time to transplant a hectare by manual vegetable transplanter comes out to be $46.28 \mathrm{man}-\mathrm{h} / \mathrm{ha}$ for tomato and $61.72 \mathrm{man}-\mathrm{h} / \mathrm{ha}$ for chilli. The time and labour requirement to transplant a hectare by conventional method comes out to be $160 \mathrm{man}-\mathrm{h} / \mathrm{ha}$ for tomato and chilli. Results revealed that the average saving of $66.25 \%$ of time and labour over conventional method. The cost of operation for transplanting tomato and chilli by manual vegetable transplanter were found to be $2168.51 \mathrm{Rs} / \mathrm{ha}$ and $2891.3 \mathrm{Rs} /$ ha respectively and the cost of operation for transplanting tomato and chilli by conventional method were found to be $5000 \mathrm{Rs} /$ ha respectively. The cost of operation was reduced with the developed prototype and saving in cost of operation was found to be $56.62 \%$ for tomato and $42.17 \%$ for chilli over conventional method.

\section{Introduction}

Vegetables play an important role in human nutrition and vegetable production is essentially a small-farm venture that benefits thousands of families in urban and rural areas. Growing vegetables in the country, offers self-employment to families who are engaged in different aspects: crop-cultivation, harvesting, transporting, preparation for the market and selling for about 175 types of vegetables. According to Horticultural Statistics at a Glance-2020, total vegetable production in India in the year 2018-2019 was 
183.17 million tonnes. It is estimated that the per capita fruits and vegetables availability in India is less than 190 to $200 \mathrm{~g}$ per day, which is far below the recommended quantity of 230 g per capita per day (Nandede et al., 2017). On other side, growth in the vegetable and fruit sectors offers considerable opportunities for increased diversification of agricultural income and nutrition in the future in Indian farming conditions. The estimated demand of vegetables in India by the end of 2020 is 220 million metric tons and this can be achieved by increasing the area under vegetable cultivation and mechanised operation of vegetable seedlings cultivation. In the past one decade, the change in cropping pattern is more towards the horticulture sector and commercial crops. Presently at most of the area is covered by hybrid seeds for vegetable cultivation, seeds are costly but gives higher yield and quality produce.

The development of Indian agriculture sector depends on the development of farm machinery. There is need of cheap and easily available farm machinery to reduce human efforts and the product damage. The available vegetable transplanter is expensive for the small-scale farmer; therefore, these farmers use traditional methods of vegetable transplanting. In India most of the farmers doing transplanting operation of vegetables with traditional methods, that methods include all operation such as making holes in mulching paper, dugout pits on bed and transplant seedling in each hole are done manually. This method of transplanting is time consuming and need maximum labour input, sometime there is lack of availability of labour. The unavailability of labour, cause delay in transplanting operation which directly affects crop production and economic condition of the farmer.

Transplanting is practice which involves the placing of seedlings either on the ridge or well-prepared seedbed, such that they start establishing their roots and survive as a separate plant. Seedlings for transplanting purposes are raised on beds in which seeds are broadcasted or dibbled in lines. According to the requirement of the procedure followed for transplanting of a particular crop or method. Seedling are then uprooted manually when they are about 4-10 weeks old and transplanted in fields. Transplanting of seedling is a manual and labour-intensive operation. Timely transplanting of vegetable crops is essential for higher yields.

The farmers need a vegetable transplanter that is simple in design, affordable and suitable for their farming conditions. Considering the small and fragmented holdings under vegetable crops and to avoid bending posture in manual transplanting, it was considered that manually operated vegetable transplanter will be suitable for adoption in Indian conditions.

Shaw (1997) developed an automatic transplanting vegetable machine with the transplanting rate of 7000 plants per hour per row unit and tested it in a greenhouse for both tomato and pepper seedling into bare ground with plastic mulch and it was found that on a regular basis, the machine resulted in $98 \%$ of good quality seedling from a tray and regularly removes all of the seedlings from the tray. This machine was designed for 7 to 8 inches total length seedlings and however some difficulties were observed with plants over 9 to 10 inches in length.

Vinay Kumar et al., (2018) developed the single row manual vegetable transplanter on three different types of vegetable crops i.e., brinjal, chilli and tomato at two different sites and compare it with traditional method of transplanting. The effective field capacity was 52.36 per cent superior over conventional method of transplanting. Field efficiency was 
found to be 91.34 and 90.63 per cent with vegetable transplanter and conventional method respectively. Labour requirement and cost of operation were also extremely reduced compared to traditional method of transplanting and results revealed average saving of 52.83 per cent of time and labour over traditional method. In agriculture, transplanting is one of the important labourintensive activity and adoption of the single row manual vegetable transplanter in the present study increased not only efficiency but cost of operation was also reduced by reducing labour engagement during transplanting.

Arjya et al., (2018) developed the Bullock Drawn Vegetable Transplanter. The machine was evaluated in the field condition with a pair of bullocks using bare root seedlings of brinjal and chilli of 10-12\% moisture content. From the field studies the average depth of planting brinjal and chilli was found to be 58$60 \mathrm{~cm}$. The plant stand and plant mortality after 21 days of transplanting was found to be 70.78-72.76 \% and 21.66- $25.66 \%$ respectively. The tray type metering mechanism maintained a plant to plant spacing of $525 \mathrm{~mm}$. Draft developed by the vegetable transplanter was $21 \mathrm{kgf}$. The field capacity and field efficiency of the developed transplanter was $0.052 \mathrm{ha} / \mathrm{h}$ and $72.20 \%$ respectively.

Anuj et al., (2018) conducted an experiment to evaluate the performance of semiautomatic vegetable transplanter and compare it with the traditional system of manual transplanting. The two-row vegetable transplanter was evaluated in the field for brinjal and chillies and compared with the manual transplanting of bare root seedling and study evaluation of transplanter revealed that field capacity of transplanter was 0.09 $0.12 \mathrm{ha} / \mathrm{h}$ with field efficiency of 64 to $75 \%$. The average plant height, number of branches per plant, plant mortality, yield, seedling missing, and leaf area were found more by machine transplanting while plant population, planting depth were found less by machine transplanting. Time saving, labour saving, lower cost of operation was observed in machine transplanting as compared to manual transplanting.

Manjuath Pai et al., (2016) developed the Semi-Automatic Vegetable Planting Machine. This planter machine has considerable potential to greatly increase productivity. The main task now is to promote this technology and have available to farmers at an affordable price. The Planter machine can be readily made from local components in workshops. By using of this machine, achievement of flexibility of distance and depth variation for different seed plantation is possible.

\section{Materials and Methods}

The present investigation entitled "Design, Development and Evaluation of Manual Vegetable Transplanter" was developed in the workshop of Sam Higginbottom University of Agriculture, Technology and Sciences, Prayagraj, U.P. The chapter deals with various materials and methods used in the experiments under following:

1. Experimental setup of manual vegetable transplanter

2. Design considerations of manual vegetable transplanter

3. Performance evaluation of manual vegetable transplanter

\section{Experimental setup of manual vegetable transplanter}

Keeping in view the design specifications, a prototype of manual vegetable transplanter was fabricated in the workshop of SHUATS using locally available materials (Fig. 1-4; 
Table 1-3).

\section{Design considerations}

The following design considerations have been considered in mind while developing the prototype:

Simple in fabrication with locally available materials and easy to use

Able to transplant vegetable seedlings in standing posture

Farmer friendly, the safety of the operator

Able to transplant seedling of different vegetable crops

Minimal force requirement for penetration into the soil surface

Easy to operate both male and female can be operated

Design of manual equipment depends on many factors like mode of operation, anthropometric data of user population, material and shape of equipment. Research has shown that there are anthropometric differences between different populations in almost every part of the human body.

Based on the conceptual view of the manual vegetable transplanter, functional requirement, the anthropometric data of the user populations of Allahabad, Uttar Pradesh (Ahmed Merza Abood et al., 2015) and taking into consideration of the specification of nursery seedlings of different vegetable crops such as tomato and chilli, the prototype was developed. The specifications of the seedlings taken into consideration for design of prototype.

Improved equipment plays an important role in farm mechanization of a country. Compatibility between size and physical strength of the users, design and dimensions of farm tools and equipment is essential to achieve enhanced performance and efficiency of man-equipment system along with better comfort and safety of operators.

The main components of the vegetable transplanter are given below:

Frame

Wheels

Frame

Seedling tray mounted on the frame

Supporting rod

Furrow covering device

Planting device

Seedling delivery tube

Hopper

Handle

Jaw opening lever (pedal)

Jaw (Opening mouth)

\section{Wheels}

The wheels are manufactured with $3.5 \mathrm{~cm}$ width of steel bar with thickness $3 \mathrm{~mm}$. The diameter of the wheel is $30 \mathrm{~cm}$. Lugs on wheels to resist sliding action and due to selfcleaning property, $2 \mathrm{~cm}$ height of lugs was attached to four wheels. The diameter of the wheel including lugs was $34 \mathrm{~cm}$.

\section{Frame}

The frame which is suitable to push the total equipment and balance the total loads in equipment. The frame is constructed with Lshaped bar with thickness of $3 \mathrm{~mm}$ and width of $3.5 \mathrm{~cm}$. The total length of the frame is 4.3 feet. The frame consists of a handle which helped to hold tight and give maximum support to push equipment.

\section{Seedling tray mounted on the frame}

The seedling frame is used to place the seedling tray. The height of the seedling 
frame is $52 \mathrm{~cm}$, width of the seedling frame is $71 \mathrm{~cm}$. Height of the seedling frame from the ground was $115.5 \mathrm{~cm}$. The seedling frame holds the 4 seedling trays and rotates $360^{\circ}$ by using $45 \mathrm{~mm}$ bearings.

\section{Supporting rod}

Seedling frame is mounted on the supporting square rod, the diameter of the square pipe was $45 \mathrm{~mm}$ and length of the square pipe is 3 feet. One end of the supporting rod is attached to frame and another end is attached to seedling frame. The seedling delivery mechanism is attached by four bars from the supporting rod.

\section{Furrow covering device}

The covering device of manually operated vegetable transplanter was designed adjustable. It was designed to allow for proper covering of the soil over the seedlings in the furrows. The length of the furrow covering device is $22 \mathrm{~cm}$, width is $22 \mathrm{~cm}$ and adjustable height is $10 \mathrm{~cm}$.

\section{Seedling delivery tube}

The dimension of seedling plays vital role to decide the diameter of seedling tube, height of jaw and apex angle. Canopy of seedling is considered to decide the diameter of seedling delivery tube. The average size of canopy is required to avoid clogging in hollow pipe. The height of seedling should not me more than $20 \mathrm{~cm}$ and seedling age from 30-40 days is preferable as the height at this stage ranges from 10-15 cm (Malunjkar et al., 2014).

For seed delivery tube, polyvinyl chloride (PVC) pipe is selected due to its light weight, easy availability and its cheapness. The diameter of tube was selected $7 \mathrm{~cm}$ on the basis of dimension of average canopy of seedlings which ranged from 21 to 53 mmand it was also provided with a hopper so that it is easy for seedling to go inside the delivery tube without any interruption and damage to the leaves of the seedlings from the upper edge of the feeding pipe of transplanter.

\section{Height of handle of vegetable transplanter from ground}

For manually operated implements, the handle is one of most important components with which the operator controls and guides the implements properly during field operations and the height of the handle of the transplanter from the ground should be designed such that during operation the operator stands erect as far as possible to reduce musculoskeletal discomfort (Dewangan et al., 2008).

The height of the handle from ground was determined as $87 \mathrm{~cm}$ and made up of MS pipe.

\section{Handle width}

It is used to hold and penetrate the jaw in the soil bed. For maximum work efficiency, hand positioning should be such that both hands are close to their neutral position. Thus, handle width depends on elbow- elbow breadth. Taking a clearance of $87 \mathrm{~cm}$ on each side, the recommended handle width was $54 \mathrm{~cm}$. The recommended grip diameter was determined as $2.5 \mathrm{~cm}$.

\section{Size of jaw mouth}

The size of jaw mouth depends on the required depth of transplanting of the different vegetable seedlings.

The required depth for transplanting is 3 to 5 $\mathrm{cm}$ for the vegetable seedlings therefore, the size of jaw mouth is taken as $20 \mathrm{cmso}$ that jaw could easily penetrate into the soil surface 
up to $5 \mathrm{~cm}$ depth.

\section{Apex angle}

The apex angle $(\Theta)$ is inclined angle formed by the two edges between the jaw and jaw opener, according to Singh (1998). It ranges between $36^{\circ}$ to $60^{\circ}$ for proper penetration of implement into the soil; therefore, apex angle of jaw was taken as $60^{\circ}$ for easy penetration without much efforts. The apex angle was found by using the angle protractor.

\section{Performance evaluation of manual vegetable transplanter}

\section{Working principle of the manual vegetable transplanter}

The main working principle of manual vegetable transplanter is pedal operated. This prototype has simple mechanism; the jaw is operated with pedal which is connected by spring. The prototype in held position with as the jaw penetrate into soil bed, pick up one seedling and drop into seedling delivery tube, then push the pedal downside and the action of pedal opens the jaw inside the soil, at that condition seedling is drop into the pit. Now pick up the implement in the same position (jaw in open position), the outermost soil from jaw comes towards the root zone of seedling, then the jaw closer covers the seedling with the soil partially. Then the furrow closer will covers the seedling with soil.

Field capacity

Field efficiency

Refilling time

Turning losses

Labour requirement

No. of plants per sq. $m$

\section{Field capacity}

Theoretical field capacity was calculated based on the speed of operation and theoretical time taken

Theoretical Field Capacity $=\frac{W \times S}{10}$

$\mathrm{W}=$ Width of operation $(\mathrm{m})$

$\mathrm{S}=$ Speed $(\mathrm{km} / \mathrm{h})$

Actual field capacity was calculated based on area covered and actual time taken for covering the area including the time lost in turning, rest and talk.

Actual Field Capacity $=\frac{\text { Actual area covered }}{\text { Actual time taken }}$ (ha/h).

\section{Field efficiency}

Field efficiency was obtained by dividing actual field capacity by the theoretical field capacity.

Field efficiency $=\frac{\text { Actual field capacity }}{\text { Theretical field capacity }} \times 100$

\section{Refilling time}

Time taken to refill the seedling tray mounted on the frame of equipment.

\section{Turning losses}

Time taken to place the equipment from one row to another row to planting.

\section{Labour requirement}

Skilled labour (man power) required to operate the vegetable planter viz., operating the planter, placing seedling tray, shifting the machine from one row to another row.

\section{No. of plants per meter length}

The total number of plants were recorded per meter length with the help of measuring tape.

\section{Results and Discussion}

The chapter deals with the results of the study which has been conducted in two phases. In 
the first phase, a manual vegetable transplanter was designed and developed. In the second phase, the developed prototype was evaluated in the field with the different types of vegetable crops i.e., tomato and chilliat SHUATS, Allahabad, Uttar Pradesh, during November, 2020 to determine its performance under actual field conditions. The results obtained during the course of these investigations are presented and discussed under the following sub heads.

Experimental setup of manual vegetable transplanter

Design considerations of manual vegetable transplanter

Performance evaluation of manual vegetable transplanter

\section{Experimental setup of manual vegetable transplanter}

The field evaluation of the manual vegetable transplanter was carried out in the field at SHUATS, Allahabad.

\section{Design considerations of manual vegetable transplanter}

The review of the literature revealed that the main problem with traditional method of transplanting was that the farmers have to work with their hands and there was lot of fatigue involved in it along with the occupational health hazards and the posture adopted during the operation was also not proper and lead to occupational health problems. Transplanting with tradition method in strenuous posture also causes severe pain in shoulders, upper back, hands and fingers.

The design of the equipment was based on the idea that it should relieve farmers from back pain and eliminate continuous sitting posture by employing standing posture to increases the work efficiency, reduce drudgery and provide comfortable working posture.

The design and fabrication of prototype of manual vegetable transplanter was based on the two main factor.

\section{Specifications of seedling}

On the basis of the canopy (floral spread) of the seedlings, the diameter of the seedling delivery tube was decided.

On the basis of the height of the seedlings the size of the jaw mouth was decided.

\section{Performance evaluation of manual vegetable transplanter}

\section{Field capacity}

The average effective field capacity for transplanting tomato and chilli with developed vegetable transplanter was 0.0057 $\mathrm{ha} / \mathrm{h}$ and $0.0029 \mathrm{ha} / \mathrm{h}$. The lower field capacity in case of chilli was due to higher plant population per unit area as compared to tomato. The mean effective field capacity was $49.12 \%$ higher over chilli.

\section{Field efficiency}

The average field efficiency for transplanting tomato and chilli with developed vegetable transplanter was $95 \%$ and $96.66 \%$, respectively.

The lowest average field efficiency was found in case of tomato with developed transplanter due to its larger floral spread (Canopy) and the seedlings of the tomato crop were more delicate therefore required more caring while transplanting.

Higher field efficiency was found in case of chilli crop with developed vegetable transplanter. However, the efficiency can be increased with more skillful operators. 


\section{Refilling time}

The time taken to replace the empty tray with the seedling tray.

\begin{tabular}{|l|l|l|l|l|}
\hline Crops & R1 (sec & R2 (sec & R3 (sec) & Avg (se \\
\hline Tomato & 8 & 10 & 9 & 9 \\
\hline Chilli & 10 & 11 & 9 & 10 \\
\hline
\end{tabular}

The maximum refilling time is $10 \mathrm{sec}$, minimum is $8 \mathrm{sec}$ and average is $9 \mathrm{sec}$ were observed in the planting of tomato seedlings.

The maximum refilling time is $11 \mathrm{sec}$, minimum is $9 \mathrm{sec}$ and average is $10 \mathrm{sec}$ were observed in the planting of chilli seedlings.

\section{Turning losses}

The loss of time during the field operation while working on borders to turn the equipment one row to another row.

\begin{tabular}{|l|l|l|l|l|}
\hline Crops & R1 (sec & R2 (sec & R3 (sec) & Avg (se \\
\hline Tomato & 8 & 10 & 12 & 10 \\
\hline Chilli & 10 & 12 & 11 & 11 \\
\hline
\end{tabular}

The maximum turning loss is $12 \mathrm{sec}$, minimum is $8 \mathrm{sec}$ and average is $10 \mathrm{sec}$ were observed in the planting of tomato seedlings. The maximum turning loss is $12 \mathrm{sec}$, minimum is $10 \mathrm{sec}$ and average is $11 \mathrm{sec}$ were observed in the planting of chilli seedlings.

\section{Labor requirement}

The time and labor requirement has been considerably reduced by use of developed vegetable transplanter and it was seen that the average time required to transplant a hectare area by developed vegetable transplanter found to be $46.28 \mathrm{man}-\mathrm{h} / \mathrm{h}$ a for tomato and $61.72 \mathrm{man}-\mathrm{h} / \mathrm{ha}$ for chilli. The time and labour requirement to transplant a hectare by conventional method comes out to be 160 man-h/ha for tomato and chilli. No. of plants per meter length

The number of plants planted in the square meter area is 4.4 for tomato and 12 for chilli.

In conclusion the results obtained in the present study on the design, development and evaluation of manual vegetable transplanter on different types of vegetable crops i.e., tomato and chilli at SHUATS, Allahabad, Uttar Pradesh during November, 2020 to determine its performance under actual field conditions are summarized below:

The present study was carried out in two phases. In the first phase, a manual vegetable transplanter was designed and developed in the workshop of SHUATS. In the second phase, the developed prototype was evaluated in the field on vegetable crops tomato and chilliat SHUATS-Allahabad. The prototype was design on the basis of conceptual design, specification of the seedlings and anthropometry data of the user's population of Allahabad (Ahmed Merza Abood et al., 2015). The anthropometric data of farm workers of the region were considered essential for design and development of manual vegetable transplanter.

The main working principle of manual vegetable transplanter was pedal operated. This prototype has simple mechanism; the jaw was operated with pedal which was connected by spring. The prototype in held position with handle as the jaw penetrate into soil bed, pickup one seedling and drop into seedling delivery tube, then push the pedal downside and the action of pedal opens the jaw inside the soil, at that condition seedling is drop into the pit. Now pick up the implement in the same position (jaw in open position), the outermost soil from the jaw comes towards the root zone of seedling, then the jaw closer covers the seedling with the soil partially. Then the furrow closer will 
covers the seedling with soil.

Table.1 Seedling parameters of the vegetable crops

\begin{tabular}{|l|c|c|}
\hline \multirow{2}{*}{ Parameters } & \multicolumn{2}{|c|}{ Names of vegetables } \\
\cline { 2 - 3 } & Tomato & Chilli \\
\hline Age of seedlings (days) & 35 & 35 \\
\hline Leaf stage (No. of leaves) & $4-6$ & $3-5$ \\
\hline Floral spread cm (Mean) & 5.28 & 2.13 \\
\hline No of plants/meter length & 2.2 & 3.3 \\
\hline Mean seedling height (cm) & 4.85 & 3.35 \\
\hline Mean seedling diameter (mm) & 1.7 & 1.1 \\
\hline Row to row distance (cm) & 60 & 45 \\
\hline Plant to plant distance $(\mathbf{c m})$ & 45 & 30 \\
\hline Variety of vegetable & Heemsona & Shimla \\
\hline
\end{tabular}

Table.2 Specification of manual vegetable transplanter

\begin{tabular}{|l|l|c|c|}
\hline S. no. & Description & Dimensions $\mathbf{( m m )}$ & Material used \\
\hline 1. & Seedling delivery tube & 600 & PVC pipe \\
\hline 2. & Hopper diameter & 70 & PVC pipe \\
\hline 3. & Handle height & 870 & MS pipe \\
\hline 4. & Jaw mouth length & 200 & MS flat \\
\hline 5. & Apex angle & $60^{\circ}$ & - \\
\hline
\end{tabular}

Table.3 Field performance of manual vegetable transplanter

\begin{tabular}{|l|c|c|}
\hline \multirow{2}{*}{ Parameters } & \multicolumn{2}{|c|}{ Transplanter } \\
\cline { 2 - 3 } & Tomato & Chilli \\
\hline Theoretical field capacity (ha/h) & 0.006 & 0.003 \\
\hline Effective field capacity (ha/h) & 0.0057 & 0.0029 \\
\hline Field efficiency (\%) & 95 & 96.66 \\
\hline Labour requirement (man-h/ha) & 46.28 & 61.72 \\
\hline Cost of operation (Rs/ha) & 2168.51 & 2891.3 \\
\hline
\end{tabular}


Fig.1 View of developed manual vegetable transplanter

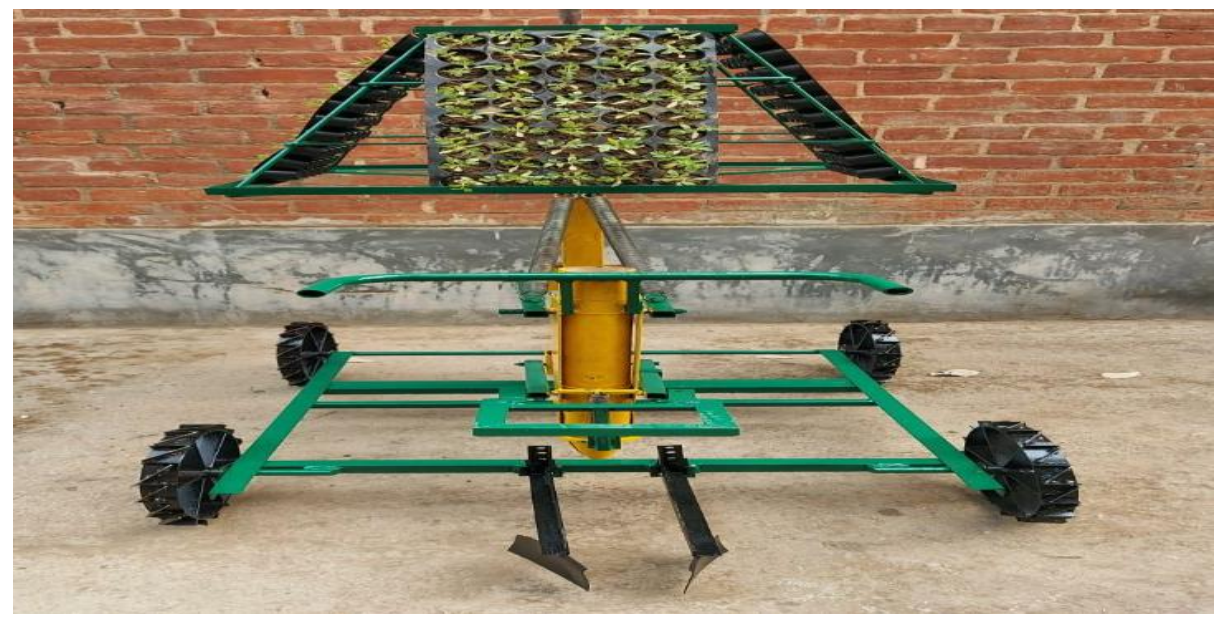

Fig.2 Graphical representation of Field Capacity for tomato and chilli

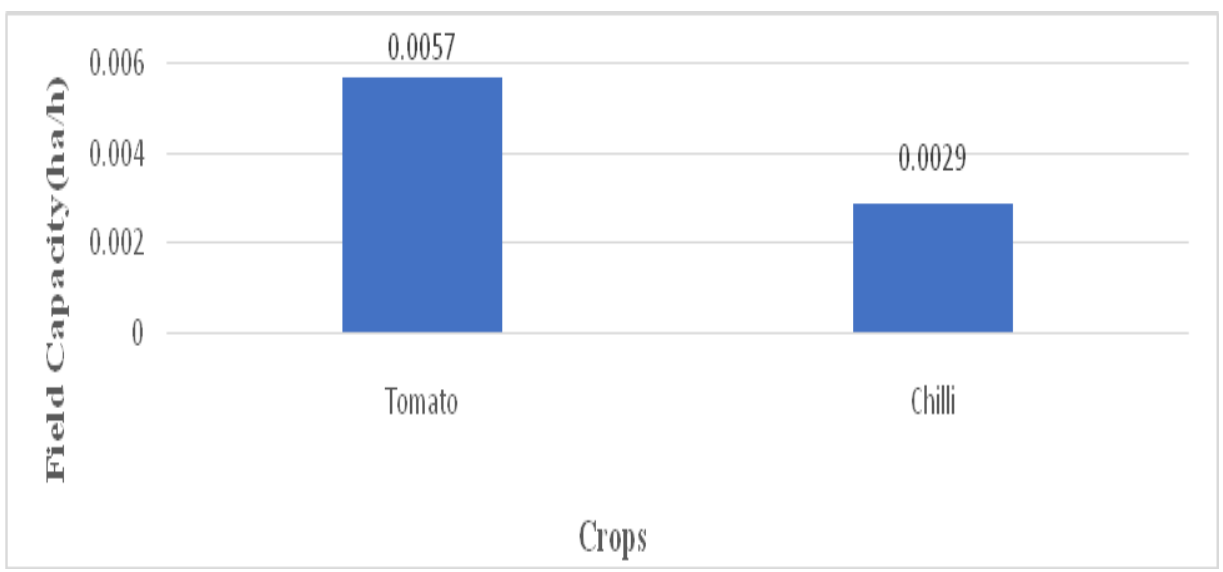

Fig.3 Graphical representation of Field Efficiency for tomato and chilli

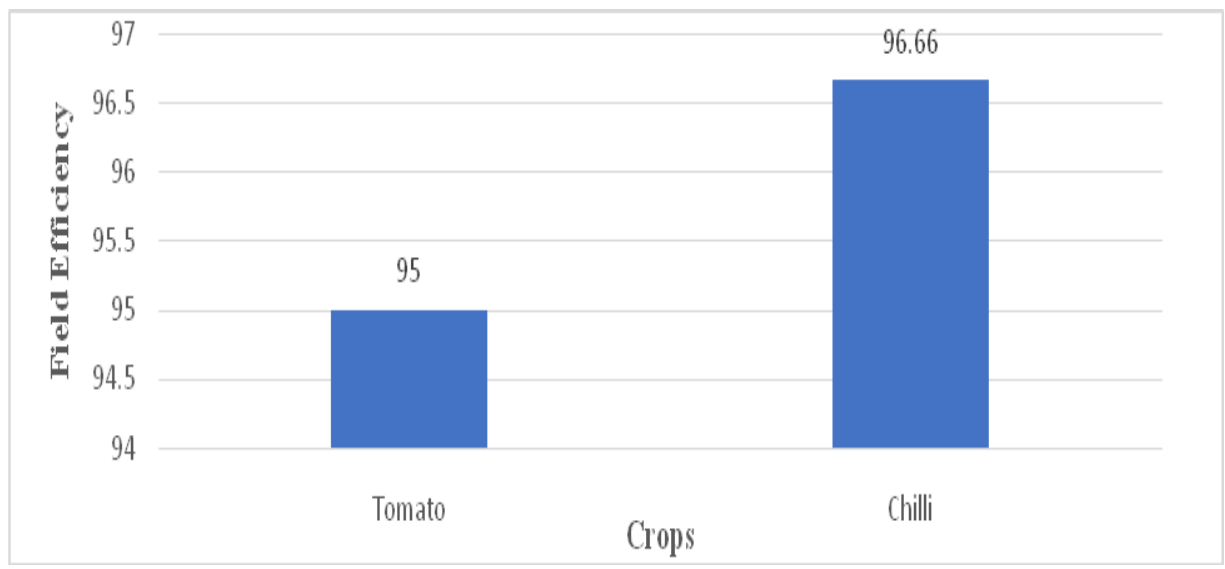


Fig.4 View of evaluation of manual vegetable transplanter at field

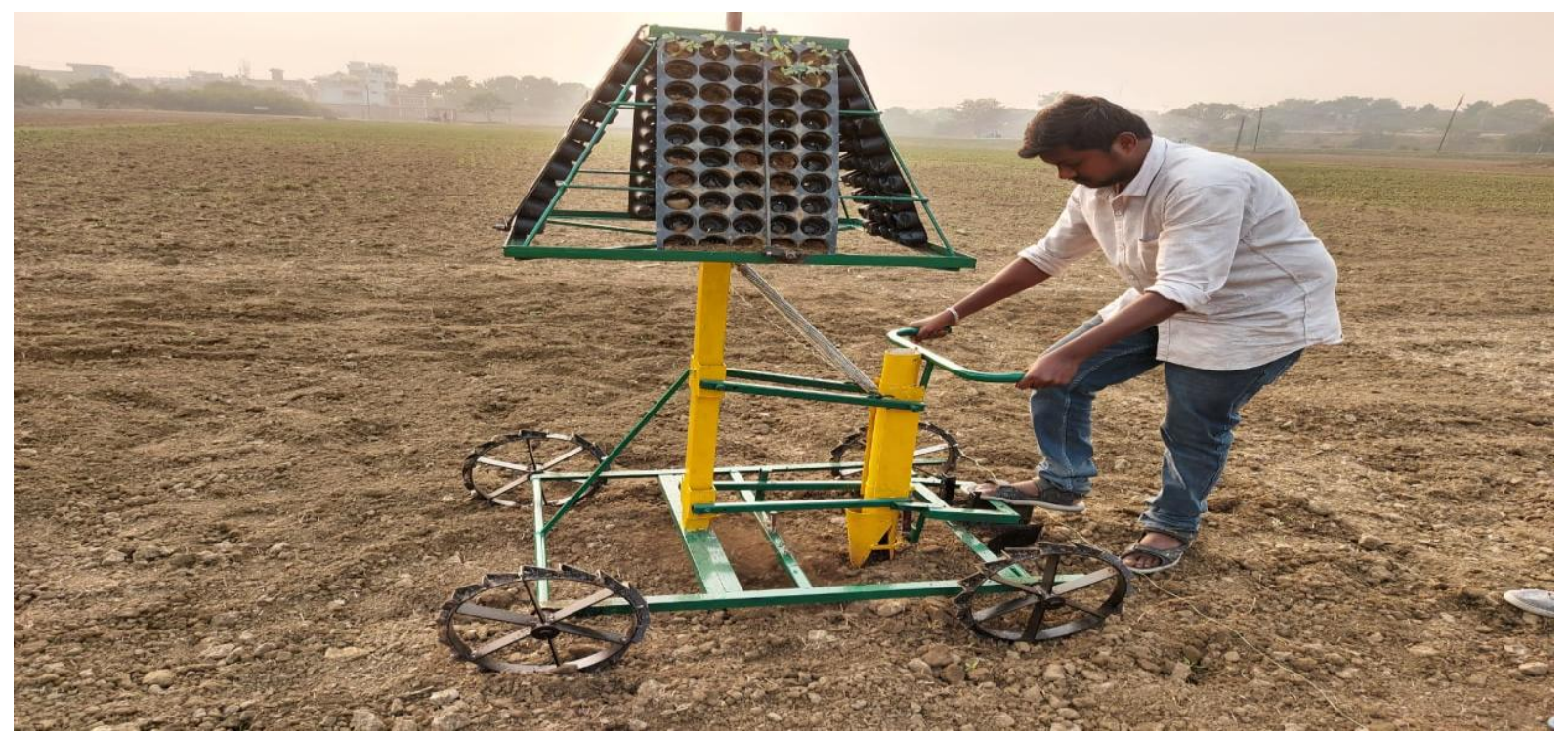

The field evaluation of the manual vegetable transplanter was carried out in the field at SHUATS, Allahabad. Field capacity and field efficiency of the developed transplanter was evaluated in the field. Mean effective field capacity was found to be 0.0043 ha/hwith manual vegetable transplanter respectively. The effective field capacity was $0.0057 \mathrm{ha} / \mathrm{h}$ for tomato and effective field capacity for chilli is $0.0029 \mathrm{ha} / \mathrm{h}$. Field efficiency was found to be $95 \%$ for tomato and $96.66 \%$ for chilli.

It can be used for transplanting many vegetable crops such as tomato, brinjal, cabbage, chilli, cucumber etc.

Vegetable seedling transplanter machine made transplanting seedling easier, faster and used less manpower.

Vegetable seedling transplanter machine made transplanting seedling easier and used less manpower.

It is used for small plots and small fields.

You can stand straight when seeding, no need to bend over and save much energy.

There is no damaged to seedling and negligible missing rate compared with automatic vegetable transplanter. It is very suitable for some plants which need plastic film mulching.

Easy operation.

\section{Acknowledgment}

The author is thankful to Assistant Professor. Dr. S. C. Moses, Department of Farm Machinery and Power Engineering, Vaugh Institute of Agricultural Engineering and Technology (VIAET), Sam Higginbottom University of Agriculture, Sciences and Technology, (SHUATS) Allahabad, (Uttar Pradesh).

\section{References}

Anuj Kumar Rai., Ashok Tripathi., Akash Agarwal., Ranjan Kumar Nirla., Himanshu Raj. and Rohit Kumar Pandey. 2018. Evaluation and performance of two row semiautomatic vegetable transplanter. International Journal of Chemical Studies 4: 125-127.

Arjya, U.S., Markandeya, M., Sangramkesari, 
S. and Debraj, B. 2018. Development and Evaluation of a Bullock Drawn Vegetable Transplanter. International Journal of Microbiology and Applied Sciences 7: 1584-1589.

Lawrange, N. S. 1997. Automatic Transplanter for Vegetables: 262-263. Manjuath, P., Sandesh, S., Chaitra, K., Chaithanya and Sandeep, S. 2016. A Study on Semi-Automatic Vegetable
Planting Machine. National Conference on Advances in Mechanical Engineering Science: 199-202.

Vinay Kumar and Jagvir Dixit. 2018. Design, Development and Fabrication of a Single Row Manual Vegetable Transplanter. Indian Journal of Hill Farming 31(1): 177-182.

\section{How to cite this article:}

Kanakam Yaswanth Kumar, V. Narendra Reddy, S. C. Moses, R. N. Aalam and Sandeep Singh. 2021. Design, Development and Evaluation of Manual Vegetable Transplanter. Int.J.Curr.Microbiol.App.Sci. 10(01): 497-508. doi: https://doi.org/10.20546/ijcmas.2021.1001.061 